\title{
SENSORY RECEPTORS IN TICKS AND MITES ${ }^{1}$
}

\author{
R. C. AXTELL, R. F. FOELIX, L. B. COONS and M. A. ROSHDY ${ }^{2}$ \\ Department of Entomology, North Carolina State University, Raleigh, N. C. USA
}

Sensory receptors in Acari are poorly known although extensive research has been reported on other Arthropoda, particularly Insecta. Our investigations of the setae on the first tarsus of the hard ticks, Amblyomma americanum (L.) and Haemaphysalis (Alloceraea) inermis Birula revealed the presence of chemo- and mechanoreceptors, judging from ultrastructural characteristics. A consistent pattern of distribution of tarsal sensilla in the region of Haller's organ was observed, by scanning electron microscopy (SEM), in the different species and life stages. Presumably chemoreceptive sensilla, resembling one type in the ticks, were found on the first tarsus of the mesostigmatid mite, Macrocheles muscaedomesticae (Scopoli).

\section{A. americanum}

Setal Pattern. The distribution of setae in the vicinity of Haller's organ on the dorsal aspect of the first tarsi is shown in Fig. 1. Both sexes of the adults (Fig. 2a) have the same number and distribution of setae as the nymphs which have been studied in detail (Foelix and Axtell,1971 and in press). The larval stage (Fig. 2b) differs in the anterior pit setae and the medial setae. The paired distal setae differ in diameter and length; the lateral (away from the body) $d_{2}$ is smaller than the mesad $d_{1}$. The distal setae were called the anterior bristle group by Lees (1948), $M_{3}$ by Zolotarev and Sinitsyna (1965) and front hair tuft (vorderes Haarbüschel) by Schulze (1941).

There are 7 anterior pit setae (terminology of Lees,1948, but called $\mathrm{X}_{2}$ by Zolotarev and Sinitsyna,1965) in the nymph and adult (Fig. 3a). For convenience, $a_{1}$ designates the lateral (behind $\mathrm{d}_{2}$ ) seta and $\mathrm{a}_{2}$ designates the seta on the opposite side of the group and behind $d_{1}$. Between $a_{1}$ and $a_{2}$, but closer to $a_{2}$, are the ret maining 5 setae. The larva has only 5 setae in the anterior pit (Fig. 3b); missing

\footnotetext{
${ }^{1}$ This research was supported by the Office of Naval Research and PHS Training Grant ES00069. Specimens of Haemaphysalis inermis were provided by Dr. Harry Hoogstraal, NAMRU-3, Cairo, UAR.

${ }^{2}$ Visiting Professor, Permanent address: Department of Zoology, Ain Shams University and NAMRU-3, Cairo, UAR.
} 


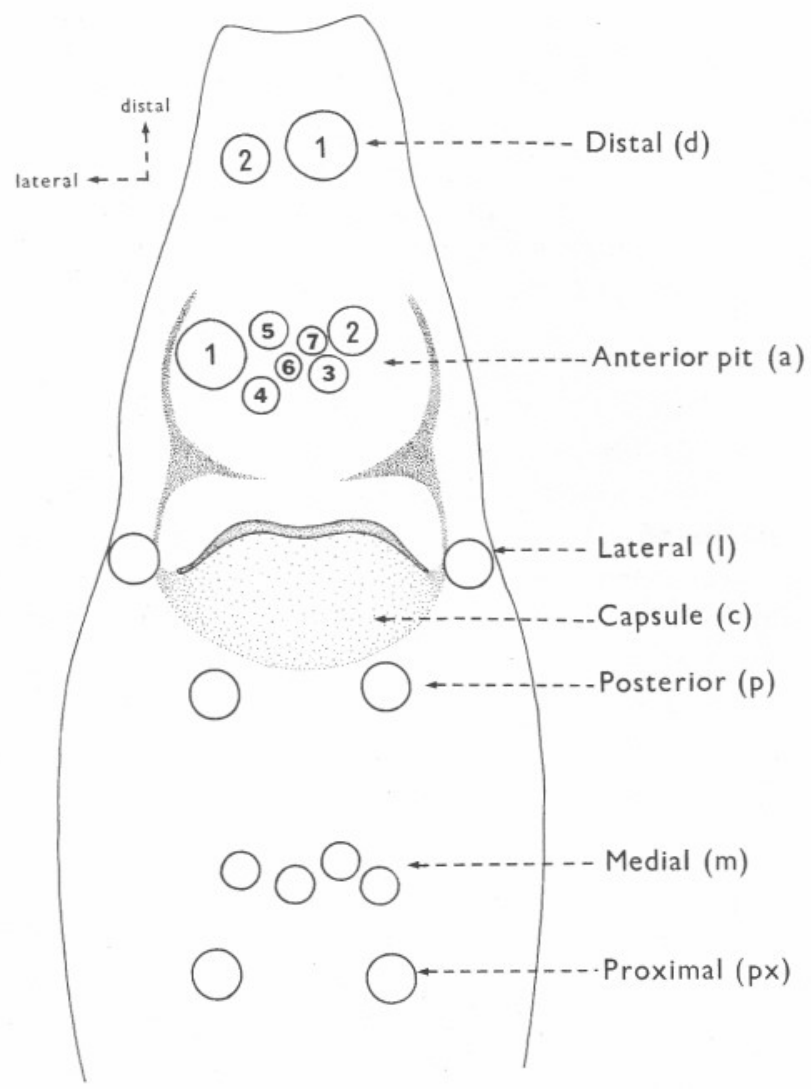

Fig. 1. 'Location and designations of Haller's organ (capsule and anterior pit) and associated setae on the dorsal surface of the first tarsi of $A$. americanum (nymph and adult).

are $a_{2}$ and either $a_{3}$ of $a_{4}$ (which is not certain).

There are 7 capsule sensilla $\left(X_{1}\right.$ of Zolotarev and Sinitsyna, 1965) in the nymph (Foelix and Axtell, in press) while the adult has 8 according to Bruce (1971) but he used only SEM and a cuticular spine could easily be mistaken for an innervated seta (= sensillum). We have not examined the capsule sensilla in the adult and larva.

On each side of the capsule is a "lateral" seta and behind the capsule are paired "posterior" setae in all life stages. Proximal to the posterior setae is a group of 4 "medial" setae in the adult and nymph (called "4-group" by Foelix and Axtell, 1971). There are only 2 medial setae in the larva. Proximal to the medials are the paired "proximal" setae in all life stages. Collectively the medial and posterior setae were called "posterior bristle group" by Lees (1948) and rear hair tuft (hinteres Haarbüschel) by Schulze (1941). The $\mathrm{X}_{6}$ of Zolotarev and Sinitsyna (1965) ap- 
parently refers to the medials in Hyalomma asiaticum if one assumes the posterior setae are absent.

Ultrastructure. The fine structure of these setae has been investigated in the nymph (Foelix and Axtell,1971 and in press). Presumably the same types of ultrastructure would be found in the larva and adult. The most distinctive setae are those with large cuticular pores ( $1200 \AA$ diam, and observable in SEM, Fig. 4) containing a "plug" (Fig. 5). Such a pore plug has not been reported in other arthropods. The setae of this type are $d_{1}, a_{1}, a_{2}$ and the capsule sensilla which have thinner walls than the others. Setae of a second type ( $a_{3}$ and $\left.a_{5}\right)$ have small pores $(100-200$ $\AA$ diam.) in longitudinal surface grooves and a spoke-wheel appearance of the cuticle shaft in cross-section. The third type of setae have apparently a single opening at the tip. This was determined for the proximal setae and may be true for $a_{4}, a_{6}$ and $a_{7}$. A fourth type includes only the medial setae which have small slit openings to the exterior from internal "vase-shaped" channels.

All of these setae are innervated by varying numbers of dendrites (2-9) which branch when there are multiple pores and are unbranched in the presence of a single opening at the tip. Morphologically they correspond to known chemoreceptors in in sects. The entrance of fine silver granules through the cuticular pores has been demonstrated in some of the sensilla (Foelix, in press).

In addition to the sensillae described above, there are several $\left(d_{2}, 1, p\right)$ with thick cuticule, several unbranched dendrites in the shaft (Fig. 6) and 2 characteristic mechanoreceptive dendrites at the base. No pore openings were found but presumably there is an opening at the tip. These sensilla are apparently combined chemo- and mechano- receptors.

The dendritic ciliary structure of all sensilla differs from other invertebrate receptors in commonly having 11 double-tubules without central elements $(11+0$ instead of $9+0$ or $9+2$ ).

\section{H. inermis}

The setal pattern in $H$. inermis (Fig. $7 \mathrm{a}, \mathrm{b}$ ) is the same as described for A. americanum. The adults (both sexes) have the same number and distribution of setae as the nymphs. The distal setae differ in the same manner; $d_{2}$ smaller than $d_{1}$. There are 4 medial setae although they are positioned slightly different than in $A$. americanum. The anterior pit contains 7 setae with $a_{1}$ and $a_{2}$ easily recognized by size, shape and position (Fig. 8a). There are 2 small pointed setae ( $a_{6}$ and $\left.a_{7}\right) ; a_{3}, a_{4}$ and $a_{3}$, could be designated on the basis of their positions.

The larva of $\boldsymbol{H}$. inermis differs from the other stages in the same manner as in A. americanum. There are 5 anterior pit setae (Fig. 8 b) with $a_{1}$ easily recognized and $a_{2}$ missing. Pores were easily observed on $a_{1}$ by SEM. The small pointed setae are $a_{6}$ and $a_{7}$, but the other 2 setae cannot be reliably designated.

The fine structure of these setae has not been determined. However, the ir locations and appearance when observed by SEM suggest they correspond to those of A. americanum. 


\section{M. muscaedomesticae}

The same types of tarsal sensilla in ticks may exist in other Acari. The tip of the first tarsus of the mesostigmatid mite M. muscaedomesticae (Fig. 9a) has 8 blunt-tipped setae (Coons, 1970) which have surface protuberances after treatment in ethanol but not after killing in hot water. These setae may be olfactory receptors; olfaction has been demonstrated for the apical setae of the first tarsus (Farish and Axtell,1966, Jalil and Rodriguez,1970). Presumably the protuberances were from pores in the wall of the setae which are probably of the type shown in cross-section in Fig. 9b (notice the 5 dendrites). This resembles closely the medial sensilla in A. americanum. Thick-walls with (Fig. 9c) and without (Fig. 9d) pores were observed in other sections of apical sensilla.

These observations on ticks and a mite demonstrate the need for additional research on the receptors in Acari. Morphological observations will provide the basis for electrophysiological and behavioral studies which are necessary for elucidation of the functions of the various types of sensilla. Observations on $\mathrm{H}$. inermis and preliminary studies on Dermacentor and Ixodes suggest considerable uniformity in setal types and distribution in the region of Haller's organ in hard ticks. Further comparative studies using A. americanum as the "model" are in progress. Similar studies are in progress on soft ticks using Argas (Persicargas) a rboreus as a "model."

\section{References}

Bruce, W.A.: Posterior capsule of Haller's organ in the lone star tick, Amblyomma americanum (Acari: Ixodidae). Florida Entomologist 54: 65-72, 1971.

C.ons, L. B.: Fine structure of selected organ systems of the mite Macrocheles muscaedomesticae (Acarina: Mesostigmata: Macrochelidae). Doct. thesis, N. C. State Univ., Raleigh, N. C., 163 p. 1970.

Farish, D.J., Axtell,R.C.: Sensory functions of the palps and first tarsi of Macrocheles muscaedomesticae (Acarina: Macrochelidae), a predator of the house fly. Ann. Entomol. Soc. Am. 59 : 165-70, 1966.

Foelix, R.F.: Permeability of tarsal sensilla in the tick Amblyomma americanum (L.)(Acarina, Ixodidae), Tissue \& Cell. (In press.)

Foelix, R.F., Axtell, R.C.: Fine structures of tarsal sensilla in the tick, Amblyomma americanum (L.). Z. Zell forsch. 14: 22-37, 1971.

Foelix, R.F., Axtell, R.C.: Ultrastructure of Haller's organ in the tick Amblyomma americanum (L.). Z. Zellforsch. (In press.)

J a lil, J., R odriguez,J.G.: Studies ot behavior of Macrocheles muscaedomesticae (Acarina: Macrochelidae) with emphasis on its attraction to the house fly. Ann. Entomol. Soc. Am. 63: $738-46,1970$.

Lees, A. D.: The sensory physiology of the sheep tick, Ixodes ricinus L. J. Exptl. Biol. 25: $145-207,1948$. 
Schulze, P.: Das Geruchsorgan der Zecken. Untersuchungen über die Abwandlungen eines Sinnesorgans und seine stammesgeschichtliche Bedeutung. Z. Morph. Ökol. Tiere 37 : $491-564,1941$.

Zolotarev, E. Kh., Sinitsyna, Ye.Ye.: Chemoreceptive organs on the fore legs of ixodid ticks. Vestn. Mosk. Univ. $20: 17-25,1965$. (In Russian). 

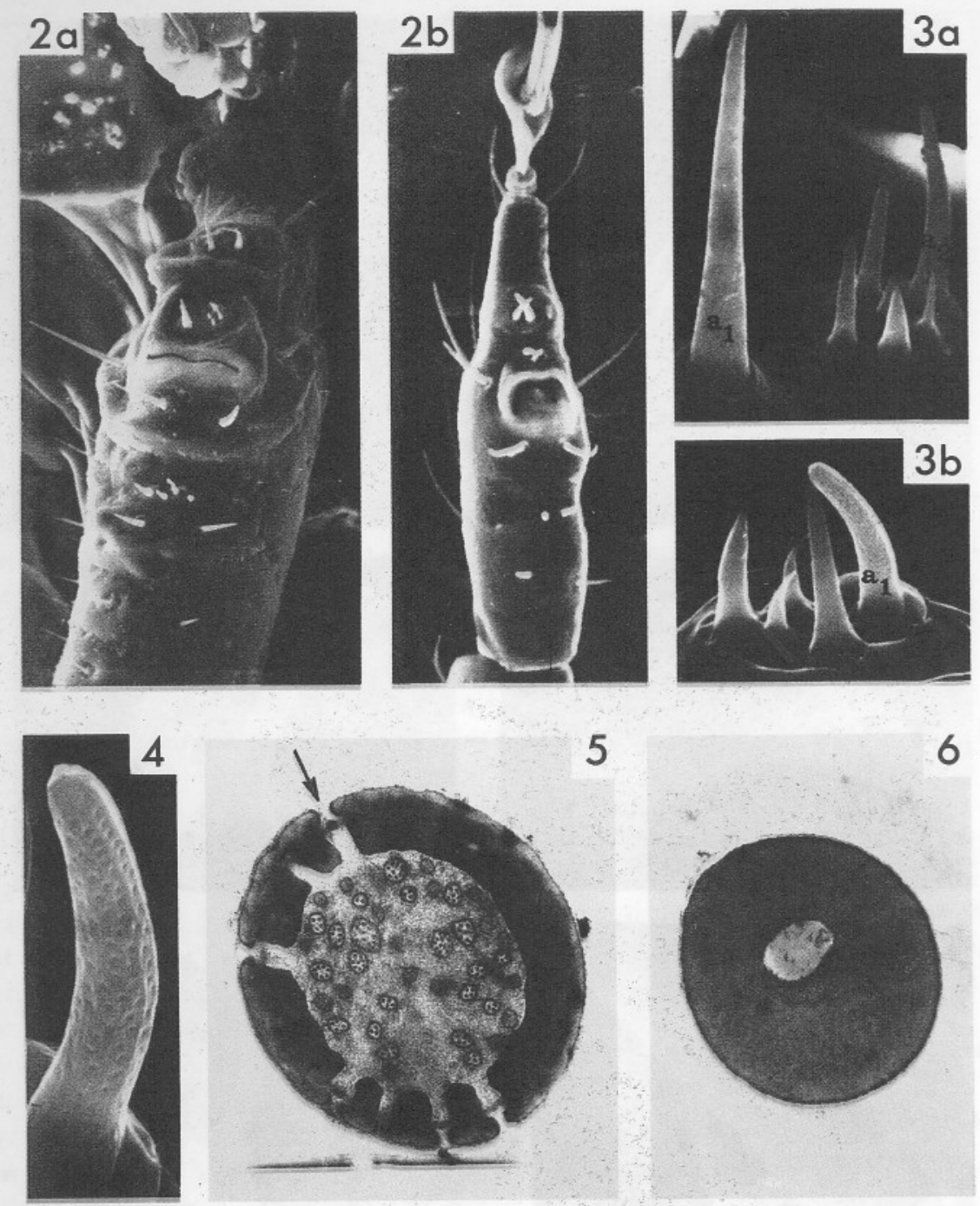

Plate I.

Fig. 2. First tarsus of A. americanum, dorsal aspect showing Haller's organ and associated setae: a) Adult female, $178 \times$; b) Larva, $216 \times$.

Fig. 3. Sensilla of anterior pit of Haller's organ of A. americanum: a) Adult (7 sensilla), $1200 \times$; b) Larva (5 sensilla), $1800 \times$.

Fig. 4. Surface pits indicating pores in the sensillum wall. ( $\mathrm{a}_{1}$ of $A$. americanum larva). $4800 \times$.

Fig. 5. Cross-section of a sensillum ( $\mathrm{a}_{1}$ of $A$. americanum nymph) showing pores, pore-plug (arrow) and dendritic branches in the lumen. $13320 \times$.

Fig. 6. Cross-section of a sensillum ( $\mathrm{d}_{2}$ of $A$. americamum nymph) which does not show pores, but a single opening at the tip is presumed. $16512 \times$. 

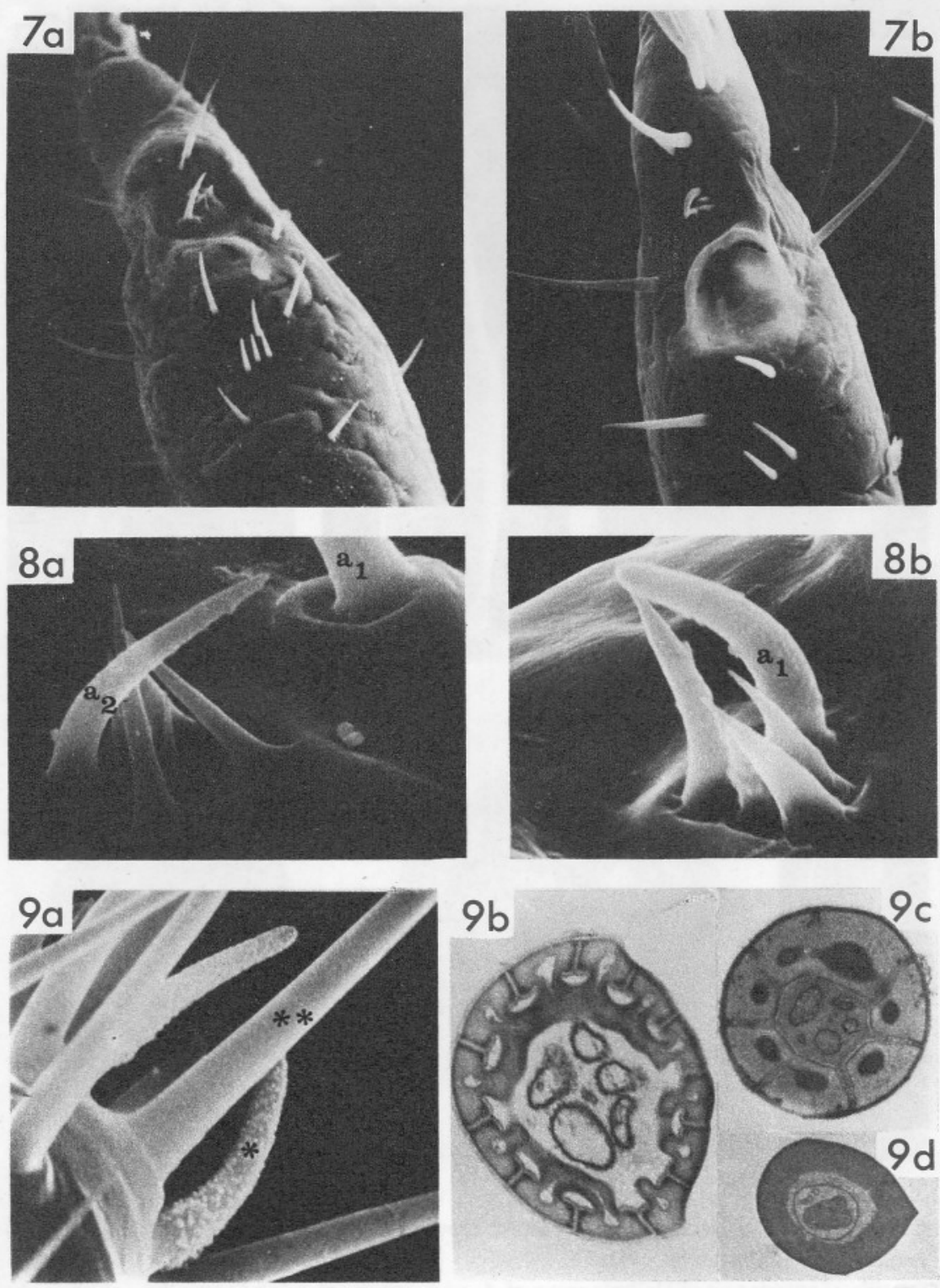

Plate II.

Fig. 7. First tarsi of $H$. inermis, dorsal aspect showing Haller's organ and associated setae: a) Adult female, $157 \times$; b) Larva, $490 \times$.

Fig. 8. Sensilla of anterior pit of Haller's organ of $H$. inermis: a) Adult (7 sensilla), $1470 \times$; b) Larva ( 5 sensilla), $3185 \times$.

Fig. 9. Setae at the tip of the first tarsus of the mesostigmatid mite, $M$. muscaedomesticae: a) Blunt pegs with protuberances $(*)$ and long pointed setae $\left({ }^{* *}\right), 1715 \times ;$ b) - d) Cross sections of tarsal setae. 